\title{
SIKAP PETANI WORTEL TERHADAP KEBERADAAN SUB TERMINAL AGRIBISNIS (STA) WATUSAMBANG DI KECAMATAN TAWANGMANGU, KABUPATEN KARANGANYAR
}

\author{
THE CARROT FARMER'S ATTITUDE ON \\ SUB TERMINAL OF AGRIBUSINESS (STA) WATUSAMBANG \\ IN TAWANGMANGU SUBDISTRICT, KARANGANYAR \\ REGENCY
}

\author{
Annisaa Dwi Prihatin ${ }^{1}$, Eny Lestari ${ }^{2}$, Hanifah Ihsaniyati ${ }^{3}$ \\ Agricultural Extension and Communication the Faculty of Agriculture \\ Sebelas Maret University \\ Email: anisaadwp@gmail.com/HP.085728405265
}

\begin{abstract}
This research are to analyze the farmers's attitude to the existence of the STA Watusambang, analyze the factors forming attitudes, and analyze the relationships between the factors forming attitudes and the farmers's attitude to the existence of STA Watusambang. The basic method used in this research was descriptive quantitative with survey technique. The location of the research was determined purposively in Blumbang Village, Tawangmangu Subdistrict, Karanganyar Regency. Sampling method used proportional random sampling, there were 60 carrot farmers chosen from each member farmer groups (4 farmer groups). The attitudeforming of carrot farmers in this research is age, formal education, personal experience, culture, and exposure to the mass media. The relationship of attitudeforming factors with the farmers's attitude could be known by using Rank Spearman analysis. The result of this research indicate that the attitude of carrot farmers against to STA Watusambang $50.0 \%$ as much as the farmer respondents have a neutral attitude. The largest percentage age farmer respondents in the age category 37-44 years, formal education and culture in low category, personal experience and influence others who are considered important in the medium category, and exposure to the mass media in the category. Relationship analysis of test results showed there are a very significant relationship $(\alpha=0,01)$ between the influence of others considered important, personal experiences, and culture with an attitude of carrot farmers against STA; There is no significant relationship between age, formal education, and the media with the attitude of carrot farmers against the STA.
\end{abstract}

Key Words: Agribusiness; Attitude; Carrot; Farmers; Rank Spearman;The market

Abstrak: Penelitian ini bertujuan untuk mengkaji sikap petani wortel terhadap STA, faktor-faktor pembentuk sikap, dan hubungan antara faktor-faktor pembentuk sikap dengan sikap petani wortel terhadap STA. Metode dasar penelitian adalah metode deskriptif kuantitatif dengan teknik survei. Lokasi penelitian ini ditentukan secara sengaja (purposive) di Desa Blumbang, Kecamatan Tawangmangu, Kabupaten 


\section{Jurnal Agritexts Volume 42 Nomer 2 Oktober 2018}

Karanganyar. Metode pengambilan sampel secara proposional random sampling sebanyak 60 petani wortel (4 kelompok tani). Faktor pembentuk sikap petani wortel dalam penelitian ini adalah umur, pendidikan formal, pengalaman pribadi, pengaruh orang lain yang dianggap penting, kebudayaan, dan terpaan media massa. Hubungan faktor pembentuk sikap dengan sikap petani dapat diketahui dengan menggunakan analisis Rank Spearman. Sikap petani wortel terhadap STA Watusambang yaitu sebanyak 50,0\% petani responden mempunyai sikap yang netral. Persentase terbesar umur petani responden dalam kategori umur 37-44 tahun, pendidikan formal dalam kategori rendah, pengalaman pribadi dalam kategori sedang, pengaruh orang lain yang dianggap penting dalam kategori sedang, kebudayaan dalam kategori rendah, dan terpaan media massa dalam kategori tinggi. Hasil uji analisis hubungan menunjukkan terdapat hubungan yang sangat signifikan (tingkat kepercayaan 99\%) antara pengaruh orang lain yang dianggap penting, pengalaman pribadi, dan kebudayaan dengan sikap petani wortel terhadap STA; terdapat hubungan yang tidak signifikan antara umur, pendidikan formal, dan media dengan sikap petani wortel terhadap STA.

Kata Kunci: Agribisnis; Pasar; Petani; Rank Spearman;Sikap; Wortel

\section{PENDAHULUAN}

Sektor agribisnis mempunyai peranan penting dalam pertumbuhan sektor pertanian, khususnya peningkatan pendapatan dan kesejahteraan petani terutama bagi petani di Indonesia. Hal ini karena mayoritas rumah tangga penduduk Indonesia dan mayoritas angkatan kerja bekerja di bidang agribisnis. Salah satu kebijakan pemerintah sebagai salah satu pe-ngembangan agribisnis yaitu pengembangan kawasan agropolitan.

Pengembangan Kawasan Agropolitan Suthomandasih merupakan salah satu kebijakan pemerintah Kabupaten Karanganyar untuk mengembangkan daerah-daerah yang berpotensi di sektor pertanian antara lain di daerah Sukuh, Cetho, Tawangmangu, Karangpandan, Matesih. Menurut Kementrian Pekerjaan Umum (2012), infrastruktur (sarana dan prasarana) dalam pengembangan kawasan agropolitan ini terdiri dari peningkatan jalan lingkungan poros desa, peningkatan jalan usaha tani, Stasiun Agribisnis (STA), peningkatan pasar ikan dan pembangunan lainnya yang memadai dan mendukung pengembangan agribisnis. Sub Terminal Agribisnis (STA) yang didirikan di Kawasan Agropolitan Suthomandasih adalah Sub Terminal Agribisnis Watusambang yang berada di Kecamatan Tawangmangu. STA Watusambang ini untuk mendukung kegiatan pemasaran dan untuk memperbaiki posisi tawar petani wortel agribisnis wortel di Kecamatan TawangmanguKecamatan Tawangmangu merupakan produsen wortel terbesar di Kabupaten Karanganyar, yaitu sebanyak 34,45 $\mathrm{Kw}$ dengan luas panen $158 \mathrm{Ha}$ (BPS Karanganyar, 2017). 


\section{Prihatin, Lestari, Ihsaniyati, Agribisnis; Pasar; Petani; Rank,נ,}

Adanya STA Watusambang, bertujuan untuk memperbaiki posisi tawar petani sehingga mampu meningkatkan kesejahteraan petani sebagai produsen di sektor pertanian. STA Watusambang ini akan berjalan secara optimal jika disana terjadi transaksi jual beli antara petani dengan pedagang dan tentunya akan ramai oleh pedagang dengan petani ketika musim panen tiba. Namun, STA Watusambang yang sedianya untuk membantu sistem pemasaran yang ada di Kecamatan Tawangmangu, belum dimanfaatkan dengan optimal oleh petani hortikultura termasuk petani wortel.

Berdasarkan survei awal yang dilakukan di lapang menunjukkan bahwa dari 11 kios yang tersedia, beberapa kios justru dimanfaatkan untuk kios non pertanian seperti untuk kios toko sepeda, onderdil motor, bengkel, dan warung makan serta masih sedikit aktivitas jual beli hasil pertanian antara petani dan pedagang.Adanya gejala kurang optimal Sub Terminal Agribisnis diduga dipengaruhi oleh berbagai faktor penghambat sebagai contoh faktor stakeholders, kondisi kelembagaan dalam STA dan lain sebagainya. Peneliti menduga ada faktor lain yang mempengaruhi berjalannya STA termasuk sikap sasaran dari dibangunnya STA itu sendiri.
Sikap positif atau negatif yang sebenarnya dimiliki oleh petani wortel terhadap STA Watusambang belum jelas diketahui. Sikap petani wortel diperlihatkan dari adanya respon atau tanggapan dalam bentuk perilaku menyenangkan atau tidak menyenang-kan, mendukung atau tidak mendukung, setuju atau tidak setuju terhadap adanya STA tersebut sebagai sebuah kelembagaan pasar pertanian bagi petani wortel di Kecamatan Tawangmangu. Untuk itu penelitian ini dilakukan guna mengetahui sikap petani wortel dan juga mengetahui faktor-faktor apa saja yaang berhubungan dengan pembentuk sikap petani wortel tersebut.

Berdasarkan uraian di atas, maka tujuan penelitian ini adalah sebagai berikut: (1)Mengetahui sikap petani wortel terhadap Sub Terminal Agribisnis (STA) Watusambang di Kecamatan TawangmanguKabupaten Karanganyar. (2)Mengetahui faktor pembentuk sikap petani wortel terhadap Sub Terminal Agribisnis (STA) Watusambang di Kecamatan Tawangmangu Kabupaten Karanganyar. (3)Mengetahui hubungan antara faktor pembentuk sikap dengan sikap petani wortel terhadap Sub Terminal Agribisnis (STA) Watusambang di Kecamatan Tawangmangu Kabupaten Karanganyar. 


\section{Jurnal Agritexts Volume 42 Nomer 2 Oktober 2018}

\section{METODE PENELITIAN}

Metode dasar yang digunakan adalah metode deskriptif kuantitatif dan metode analisis dengan teknik penelitian survei. Penentuan lokasi penelitian dilakukan secara sengaja (purposive) yaitu di Kecamatan Tawangmangu Kabupaten Karanganyar dengan pertimbangan bahwa letak Sub Terminal Agribisnis (STA) di Kawasan Agropolitan Suthomandasih. Populasi dalam penelitian ini adalah petani yang membudidayakan wortel di Desa Blumbang Kecamatan Tawangmangu dengan pertimbangan bahwa desa tersebut yang telah menjadi percontohan pusat Pengembangan Kawasan Agropolitan khususnya komoditas. Desa Blumbang juga menjadi sentra produksi wortel terbanyak di Kecamatan Tawangmangu. Penentuan sampel dalam penelitian ini dilakukan dengan menggunakan metode proportional random sampling. Penarikan sampel dilakukan secara acak dengan melalui daftar anggota masingmasing kelompok tani. Jenis dan sumber data yang digunakan dalam penelitian ini adalah data primer dan data sekunder. Teknik pengumpulan data yang digunakan dalam penelitian ini adalah observasi, wawancara dan pencatatan. Penelitian ini menggunakan uji korelasi Rank spearman.
HASIL DAN PEMBAHASAN

Desa Blumbang terdiri dari 1 desa dan 3 dusun atau lingkungan, 5 kelompok tani, 1 gapoktan, 4 RW dan 24 RT. Desa Blumbang berada pada ketinggian $1.350 \mathrm{~m}$ diatas permukaan laut dengan suhu antara $17^{\circ}-26^{\circ} \mathrm{C}$. Desa Blumbang juga memiliki letak yang strategis dengan pusat pemerintahan Kecamatan Tawangmangu yaitu hanya berjarak $1,5 \mathrm{Km}$. Jumlah penduduk di Desa Blumbang tahun 2016 sebanyak 3.973 jiwa dalam 1.286 KK terdiri dari penduduk laki-laki sebesar 2.028 jiwa dan penduduk perempuan sebanak 1.945 jiwa. Jumlah penduduk terbesar di Desa Blumbang adalah penduduk dengan usia 15-65 tahun dengan jumlah 2.334 jiwa. Untuk usia 0-15 tahun sejumlah 1.400 jiwa dan usia 65 tahun ke atas sejumlah 239 jiwa (Monografi Desa Blumbang, 2016).

Bangunan STA Watusambang yang ada di Kecamatan Tawangmangu terdiri dari 11 kios dan ruang kantor dengan menempati lahan seluas $1.700 \mathrm{~m}^{2}$. Sampai saat ini pengoperasian STA masih sebagai tempat transaksi/pertemuan antara pembeli dan ped-agang, namun transaksi pemasaran ini bukan dalam bidang pertanian melainkan transaksi non pertanian. Penggunaan kios di STA tercatat masih kurang optimal 
penggunaannya yaitu dari 11 kios yang ada, 4 kios terisi oleh toko onderdil sepeda, bengkel, dan warung makan, sedangkan yang lainnya masih kosong. Masih sebagian kecil petani yang memanfaatkan fasilitas STA baik mencuci hasil panen maupun untuk memasarkan produknya. Wilayah kerja STA Watusambang meliputi 10 desa yang ada di Kecamatan Tawangmangu.

Tabel 1. Distribusi Responden Berdasarkan Sikap Petani Wortel terhadap Keberadaan STA Watusambang

\begin{tabular}{|c|c|c|c|c|}
\hline No. & Kategori Sikap & Interval Skor & Jumlah (orang) & Persentase (\%) \\
\hline \multirow[t]{6}{*}{1.} & Sangat Buruk & $4,0-7,1$ & 3 & 5,0 \\
\hline & Buruk & $7,2-10,3$ & 11 & 18,3 \\
\hline & Netral & $10,4-13,5$ & 13 & 21,7 \\
\hline & Baik & $13,6-16,7$ & 20 & 33,3 \\
\hline & Sangat Baik & $16,8-20,0$ & 13 & 21,7 \\
\hline & & Jumlah & 60 & 100 \\
\hline & Sangat Buruk & $20-36$ & 3 & 5,0 \\
\hline & Buruk & 37- 53 & 24 & 40,0 \\
\hline & Netral & $54-70$ & 22 & 36,7 \\
\hline & Baik & $71-87$ & 11 & 18,3 \\
\hline & Sangat Baik & $88-104$ & 0 & 0 \\
\hline & & Jumlah & 60 & 100 \\
\hline & Sangat Buruk & $32-57$ & 3 & 5,0 \\
\hline & Buruk & $58-83$ & 16 & 26,7 \\
\hline & Netral & 84-109 & 30 & 50,0 \\
\hline & Baik & $110-135$ & 11 & 18,3 \\
\hline & Sangat Baik & $136-160$ & 0 & 0 \\
\hline & & Jumlah & 60 & 100 \\
\hline \multicolumn{2}{|c|}{ 4. Sikap Petani Wortel terhadap Sangat Buruk } & $32-57$ & 3 & 5,0 \\
\hline & Buruk & $58-83$ & 16 & 26,7 \\
\hline & Netral & 84-109 & 30 & $\mathbf{5 0 , 0}$ \\
\hline & Baik & $110-135$ & 11 & 18,3 \\
\hline & Sangat Baik & $136-160$ & 0 & 0 \\
\hline & & Jumlah & 60 & 100 \\
\hline
\end{tabular}

Sumber: Sumber: Analisis Data Primer Tahun 2017

Sikap Petani Wortel terhadap STA Watusambang

Hasil penelitian menunjukkan bahwa persentase terbesar sikap petani terhadap tujuan STA Watusambang dalam kategori baik yaitu sebesar $33,33 \%$ atau sebanyak 20 orang.Melalui tujuan STA Watusambang, petani wortel merasa sedikit diperhatikan dalam hal pemasaran. Selama ini program pemerintah sebagian besar program mengenai budidaya usahatani seperti program varietas unggul baru, program pupuk, dan program pengembangan olahan wortel. Adanya STA Watusambang, petani merasa diperhatikan kesejahteraannya terutama dalam memperbaiki pemasaran wortel selama ini. Jika pelaksanaannya nanti kurang optimal, dan petani merasa kurang mendapatkan manfaat maka akan merubah sikap petani terhadap STA Watusambang. Jadi sikap baik atau setuju petani wortel terhadap tujuan adamya STA 


\section{Jurnal Agritexts Volume 42 Nomer 2 Oktober 2018}

Watusambang saat ini merupakan sikap yang sementara waktu.

Hasil penelitian menunjukkan bahwa persentase terbesar sikap petani terhadap tujuan STA Watusambang tergolong dalam kategori buruk yaitu sebesar 40,0\% atau sebanyak 24 orang. Pelaksanaan STA Waatusambang, lebih banyak melibatkan para ketua kelompok tani saja atau koordinasi pemasaran di desa, sehingga petani wortel tidak merasa dilibatkan dalam koordinasi pelaksanaan STA Watusambang. Petani juga berpendapat bahwa pendirian Sub Terminal Agribisnis (STA) Watusambang, kurang sesuai dengan kebutuhan petani wortel dalam memperbaiki pemasaran wortel.

Hasil penelitian menunjukkan bahwa persentase terbesarsikap petani terhadap tujuan STA Watusambang tergolong dalam kategori buruk yaitu sebesar $41,7 \%$ sebanyak 25 petani. Adanya Sub Terminal Agribisnis (STA) Watusambang dirasakan petani masih kurang memberikan manfaat dalam menunjang pemasaran wortel sendiri. STA Watu- sambang belum bisa membantu petani dalam memperpendek jaringan pemasaran serta belum bisa memberikan solusi pemasaran yang mempermudah petani wortel.

Hasil penelitian menunjukkan bahwa persentase terbesar sikap petani terhadap tujuan STA Watusambang tergolong dalam kategori buruk yaitu sebesar $50,0 \%$ sebanyak 30 petani. Petani wortel merasa senang dan setuju akan adanya STA Watusambang ini karena ada harapan kesejahteraan petani wortel dalam pemasaran akan lebih baik. Namun disisi lain, petani kurang setuju dengan melihat pelaksanaan STA yang terjadi selama ini. Petani beranggapan STA ini masih kurang praktis jika diterapkan dalam inovasi pemasaran wortel. Petani wortel juga beranggapan bahwa keberadaan STA Watusambang ini dirasa petani kurang sesuai dengan kebutuhan petani dalam membantu pemasaran wortel. Program pemerintah seharusnya lebih mempermudah petani dan meringankan petani dalam pemasaran wortel. 
Prihatin, Lestari, Ihsaniyati, Agribisnis; Pasar; Petani; Rank,,,

Tabel 2. Distribusi Responden Berdasarkan Faktor-Faktor Pembentuk Sikap Petani Wortel di Desa Blumbang, Kecamatan Tawangmangu

\begin{tabular}{|c|c|c|c|c|c|}
\hline No & Faktor-faktor & Skor & Kategori & Frekuensi (orang) & $\begin{array}{l}\text { Persentase } \\
(\%)\end{array}$ \\
\hline \multirow[t]{5}{*}{1.} & Umur & 1 & $29-36$ & 14 & 23,3 \\
\hline & & 2 & $37-44$ & 21 & 35,0 \\
\hline & & 3 & $45-51$ & 11 & 18,3 \\
\hline & & 4 & $52-59$ & 11 & 18,3 \\
\hline & & 5 & $\geq 60$ & 3 & 5,0 \\
\hline \multirow[t]{5}{*}{2.} & Pendidikan Formal & $8,0-14,3$ & Sangat Rendah & 1 & 1,7 \\
\hline & & $14,4-20,7$ & Rendah & 10 & 16,7 \\
\hline & & $21,8-27,1$ & Sedang & 26 & 43,3 \\
\hline & & $27,2-33,5$ & Tinggi & 23 & 38,3 \\
\hline & & $33,6-40,0$ & Sangat Tinggi & 0 & 0 \\
\hline \multirow[t]{5}{*}{3.} & Pengalaman Pribadi & $8,0-14,3$ & Sangat Rendah & 1 & 1,7 \\
\hline & & $14,4-20,7$ & Rendah & 10 & 16,7 \\
\hline & & $21,8-27,1$ & Sedang & 26 & 43,3 \\
\hline & & $27,2-33,5$ & Tinggi & 23 & 38,3 \\
\hline & & $33,6-40,0$ & Sangat Tinggi & 0 & 0 \\
\hline \multirow[t]{5}{*}{4.} & Pcngaruh Orang lain yang & $22,0-39,5$ & Sangat Rendah & 1 & 1,7 \\
\hline & Dianggap Penting & $39,6-57,1$ & Rendah & 10 & 16,7 \\
\hline & & $57,2-74,7$ & Sedang & 26 & 41,9 \\
\hline & & $74,8-92,3$ & Tinggi & 22 & 36,7 \\
\hline & & $92,4-110,0$ & Sangat Tinggi & 1 & 1,7 \\
\hline \multirow[t]{5}{*}{5.} & Kebudayaan & $7,0-12,5$ & Sangat Rendah & 5 & 8,3 \\
\hline & & $12,6-18,2$ & Rendah & 31 & 51,7 \\
\hline & & $18,3-23,9$ & Sedang & 18 & 30,0 \\
\hline & & $24,0-29,6$ & Tinggi & 6 & 10,0 \\
\hline & & $29,7-35,0$ & Sangat Tinggi & 0 & 0 \\
\hline \multirow[t]{5}{*}{6.} & Terpaan Media Massa & $3,0-5,3$ & Sangat Rendah & 0 & 0 \\
\hline & & $5,4-7,7$ & Rendah & 12 & 20,0 \\
\hline & & $7,8-10,1$ & Sedang & 18 & 30,0 \\
\hline & & $10,2-12,5$ & Tinggi & 21 & 35,0 \\
\hline & & $12,6-15,0$ & Sangat Tinggi & 6 & 10,0 \\
\hline
\end{tabular}

Sumber: Analisis Data Primer Tahun 2017

\section{FaktorPembentukSikapPetaniWortel}

Hasil penelitian menunjukkan persentase terbesar umur petani responden dalam kategori umur 3744 tahun yaitu sebesar $35,0 \%$ atau sebanyak 21 orang. Notoatmodjo (2003) menyatakan bahwa semakin cukup umur, tingkat kemampuan dan kematangan seseorang akan lebih tinggi dalam berpikir dan menerima informasi. Sehingga semakin dewasa umur petani, maka akan mempermudah petani dalam menerima informasi baru terutama inovasi baru termasuk dalam hal pemasaran pertanian.

Hasil penelitian menunjukkan persentase terbesar pendidikan peta- ni responden dalam kategori pendidikan rendah atau tamat SD yaitu sebesar 38,3\% atau sebanyak 23 orang. Melalui pendidikan formal yang cukup, petani bisa memiliki kemampuan merencanakan usaha tani dengan matang sehingga dapat mengurangi resiko usahataninya. Namun berbeda jika pendidikan formal petani rendah, menyebabkan usaha tani dilakukan tanpa perencanaan yang matang.

Hasil penelitian menunjukkan persentase terbesar pengalaman pribadi petani wortel dalam kategori sedang yaitu sebesar $43,3 \%$ atau sebanyak 26 orang. Menurut informasi yang didapat, pengalaman 


\section{Jurnal Agritexts Volume 42 Nomer 2 Oktober 2018}

kegagalan dan keberhasilan petani wortel dalam usahatani sudah dialami petani cukup panjang setara dengan lamanya petani dalam usahatani. Kegagalan dan keberhasilan dalam program pemerintah termasuk program budidaya varietas unggul baru wortel, dan pupuk baru.

Hasil penelitian menunjukkan persentase terbesar pengaruh pengaruh orang lain yang dianggap penting oleh petani responden dalam kategori sedang yaitu sebesar $41,9 \%$ atau sebanyak 26 orang. Cukupnya pengaruh ini karena petani cukup dalam meminta saran maupun masukan kepada orang lain yang dianggap penting baik dalam hal pemasaran maupun usahatani. Sedangkan peran keluarga dalam pengambilan usahatani selalu menjadi pihak pertama dalam meminta pertimbangan dalam keputusan yang diambil petani. Peran petani lain cenderung hanya sebagai pembanding dalam pengambilan keputusan berusahatani petani. Namun yang menjadi kendala adalah masih kurangnya pengetahuan inovasi maupun info tentang pemasaran wortel oleh PPL dan Ketua Kelompok tani.

Hasil penelitian menunjukkan persentase terbesar kebudayaan petani responden dalam kategori rendah yaitu sebesar $51,7 \%$ atau sebanyak 31 orang. Hal ini menunjukkan bahwa kebudayaan yang mendukung pe-masaran wortelnya ke STA masih jarang dilakukan oleh petani. Kebudayaan-kebudayaan yaitu melakukan pembukuan usaha tani, mengunjungi STA, menjual wortel ke STA, dan frekuensi petani pergi keluar kecamatan dalam rangka pemasaran wortel maupun kegiatan yang lain. Petani lebih sering melakukan pemasaran wortel dengan sistem tebas yang tentunya akan menghambat petani dalam menerima inovasi baru terutama dalam sistem penjualan wortelnya. Kebiasaan turun temurun petani dengan cara menjual langsung dengan sistem tebas kepada pedagang penebas tidak mudah dirubah karena pandangan petani wortel lebih mudah, praktis, dan tidak perlu memikirkan biaya yang lain.

Hasil penelitian menunjukkan persentase terbesar terpaan media massa petani responden termasuk dalam kategori tinggi yaitu sebesar $35 \%$ atau sebanyak 21 orang. Akses petani terhadap media massa yang ada di sekitarnya sudah baik. Selama ini informasi yang didapat oleh petani di media massa mengenai perbaikan cara budidaya pertanian misalnya pembasmian hama yang tepat, dan pemilihan bibit yang sesuai dengan sertifikasi benih. Petani sadar akan kebutuhan informasi mengenai pertanian wortelnya, namun terkadang waktu yang dimiliki oleh petani tidak cukup untuk 


\section{Prihatin, Lestari, Ihsaniyati, Agribisnis; Pasar; Petani; Rank,,,}

mengakses informasi dari media serta informasi di media terkadang tidak sesuai dengan apa yang dibutuhkan oleh petani saat itu.

Tabel 3. Analisis Hubungan Antara Faktor Pembentuk Sikap dengan Sikap Petani Wortel terhadap Keberadaan Sub Terminal Agribisnis (STA) Watusambang

\begin{tabular}{|c|c|c|c|c|c|c|c|c|c|}
\hline \multirow{3}{*}{ No } & \multirow{3}{*}{$\begin{array}{c}\text { Variabel Faktor Pembentuk } \\
\text { Sikap }\end{array}$} & \multicolumn{8}{|c|}{ Sikap petani wortel terhadap STA Watusambang } \\
\hline & & \multicolumn{2}{|c|}{ Tujuan } & \multicolumn{2}{|c|}{ Pelaksanaan } & \multicolumn{2}{|c|}{ Manfaat } & \multicolumn{2}{|c|}{$\mathrm{Y}_{\text {tot }}$} \\
\hline & & $r_{s}$ & $\mathrm{t}_{\text {hitung }}$ & $r_{s}$ & $\mathrm{t}_{\text {hitung }}$ & $r_{s}$ & $\mathrm{t}_{\text {hitung }}$ & $r_{s}$ & $\mathrm{t}_{\text {hitung }}$ \\
\hline 1 & Umur (X1) & 0,182 & 0,997 & 0,140 & 0,774 & 0,240 & 1,354 & 0,225 & 1,759 \\
\hline 2 & Pendidikan formal (X2) & $0,381 * *$ & 1,747 & 0,192 & 1,072 & 0,128 & 0,707 & 0,212 & 1,652 \\
\hline 3 & Pengalaman Pribadi (X3) & 0,249 & 0,980 & $0,420 * *$ & 2,535 & $0,364 * *$ & 2,141 & $0,450 * *$ & 3,838 \\
\hline 4 & $\begin{array}{l}\text { Pengaruh orang yang } \\
\text { dianggap penting (X4) }\end{array}$ & $0,624 * *$ & 2,288 & $0,311^{*}$ & 1,792 & $0,535^{* *}$ & 3,468 & $0,503^{* *}$ & 4,432 \\
\hline 5 & Kebudayaan (X5) & 0,238 & 0,775 & $0,553 * *$ & 3,635 & $0,320 *$ & 1,850 & $0,498 * *$ & 4,374 \\
\hline 6 & Terpaan media massa (X6) & $0,324 *$ & 2,608 & 0,171 & 1,322 & 0,156 & 1,203 & 0,223 & 1,742 \\
\hline
\end{tabular}

Sumber: Analisis Data Primer Tahun Tahun 2017

Hubungan antara Faktor Pembentuk Sikap dengan Sikap Petani Wortel Terhadap Keberadaan Sub Terminal Agribisnis (STA) Watusambang

\section{Berdasarkan analisis data} primer, dapat diketahui bahwa nilai rs adalah sebesar 0,225 dengan $t$ hitung $(1,759)<t$ tabel $(2,002)$ sehingga terdapat hubungan yang tidak signifikan antara umur dengan sikap petani wortel terhadap keberadaan Sub Terminal Agribisnis (STA) Watusambang. Perubahan umur petani yang semakin bertambah, tidak merubah sikap petani wortel terhadap keberadaan STA Watusambang. Apabila umur petani bertambah tua, belum tentu sikap petani wortel juga akan berubah lebih baik atau lebih buruk dibanding sebelumnya. Hasil penelitian ini tidak sesuai dengan pernyataan Notoatmodjo (2003) bahwa semakin cukup umur, tingkat kemampuan dan kematangan seseorang akan lebih tinggi dalam berpikir dan menerima informasi. Petani yang lebih muda biasanya akan cenderung lebih produktif dan lebih bersemangat dibandingkan dengan petani yang usianya lebih tua.

Berdasarkan hasil analisis, dapat diketahui bahwa nilai $t$ hitung $(1,652)<t$ tabel $(2,002)$, pada taraf signifikansi $95 \%$ dengan nilai $r_{s}$ sebesar 0,212 sehingga terdapat hubungan yang signifikan tidak antara pendidikan formal terakhir yang ditempuh oleh petani wortel dengan sikap petani wortel terhadap keberadaan Sub Terminal Agribisnis (STA) Watusambang. semakin tinggi tingkat pendidikan formal petani tidak menjamin semakin positif sikap petani wortel terhadap inovasi pemasaran termasuk informasi STA Watusambang. Namun hasil penelitian ini tidak sesuai dengan 


\section{Jurnal Agritexts Volume 42 Nomer 2 Oktober 2018}

pendapat dari Soekartawi (1984) pendidikan formal merupakan sarana belajar, dimana selanjutnya diperkirakan akan menanamkan pengertian sikap yang menguntungkan menuju penggunaaan praktek pertanian yang lebih modern. Kecenderungan bahwa petani yang mempunyai tingkat pendidikan lebih tinggi akan lebih mudah mengetahui kegunaan teknologi yang diperkenalkan dibanding petani dengan pendidikan yang rendah.

Berdasarkan hasil analisis data primer, dapat dilihat nilai $t_{\text {hitung }}$ $(3,838)>t_{\text {tabel }}(2,663)$, pada taraf signifikansi $99 \%$ dengan nilai $r s$ sebesar 0,450 sehingga dapat disimpulkan bahwa terdapat hubungan yang signifikan antara pengalaman pribadi dengan sikap petani wortel terhadap keberadaan Sub Terminal Agribisnis (STA) Watusambang. Semakin tinggi tingkat pengalaman pribadi petani wortel, akan merubah sikap petani wortel terhadap keberadaan STA Watusambang ini. Hasil penelitian di lapang tersebut memperkuat pendapat dari Mahmud (1990), mengemukakan bahwa ke-banyakan aktivitas kita sehari-hari bergantung pada pengalaman yang terdahulu. Kemudian kita mereaksikan kepada isyarat dan lambang daripada kepada keseluruhan stimulus aslinya.

Berdasarkan hasil analisis data primer, dapat dilihat nilai $t_{\text {hitung }}$ $(4,432)>t_{\text {tabel }}(2,663)$, pada taraf signifikansi $99 \%$ dengan nilai rs sebesar 0,503 . Sehingga dapat disimpulkan bahwa terdapat hubungan yang signifikan antara pengaruh orang lain yang dianggap penting dengan sikap petani terhadap keberadaan Sub Terminal Agribisnis (STA) Watusambang. Hal ini menunjukkan bahwa semakin tinggi tingkat pengaruh orang lain yang dianggap penting oleh petani, semakin baik pula sikap yang dimiliki oleh petani wortel. Hal tersebut membuktikan bahwa pengaruh orang lain yang dianggap penting oleh petani mampu merubah sikap petani wortel terhadap keberadaan Sub Terminal Agribisnis (STA) Watusambang.

Kondisi dilapang menunjukkan pengaruh orang lain yang dianggap penting dalam kategori sedang, sedangkan sikap petani wortel terhadap STA Watusambang dalam kategori netral. Petani kurang mendapatkan informasi yang dibutuhkan dari orang lain yang dianggap penting tersebut. Hasil penelitian tersebut mendukung pendapat dari Zuchdi (1995) bahwa sikap positif seseorang dapat timbul apabila ada interaksi yang bermakna dengan orang-orang yang dianggap penting artinya dapat diperoleh apa yang dibutuhkan dari orang yang dianggap penting tersebut dan tidak terjadi perrtentangan. 


\section{Prihatin, Lestari, Ihsaniyati, Agribisnis; Pasar; Petani; Rank,נ,}

Berdasarkan hasil analisis data primer, dapat dilihat nilai $t$ hitung $(4,374)>t$ tabel $(2,663)$, pada taraf signifikansi $99 \%$ dengan nilai rs sebesar 0,498. Sehingga dapat disimpulkan bahwa terdapat hubungan yang signifikan antara kebudayaan terhadap sikap petani wortel terhadap keberadaan Sub Terminal Agribisnis (STA) Watusambang. Semakin sering petani mengunjungi STA Watusambang dan juga semakin sering petani wortel keluar daerah guna mencari informasi pasar wortel maupun diluar kepentingan tersebut maka semakin baik pula sikap petani dalam menerima kelembagaan baru pasar pertanian termasuk STA Watusambang ini.

Kebudayaan-kebudayaan yang men-dukung petani memiliki sikap yang positif terhadap STA masih jarang dilakukan. Masih sedikit petani yang melakukan perencanaan usahataninya, masih sedikit petani yang mengunjungi Sub Terminal Agribisnis (STA) Watusambang dan masih sedikit petani yang sering ke luar kecamatan dalam rangka memperoleh informasi pemasaran wortel maupun diluar mencari informasi pasar wortel di kecamatan lain. Kebudayaan-kebudayaan petani wortel tersebut perlu dikembangkan dan ditingkatkan guna pentingnya memperoleh informasi pasar bagi petani wortel sendiri. Hasil penelitian ini sejalan dengan pendapat Azwar
(1995) bahwa kebudayaan tanpa kita sadari telah mewarnai sikap anggota masyarakatnya karena kebudayaan yang memberikan corak pengalaman individu-individu yang menjadi anggota kelompok masyarakat asuhannya. Kebudayaan pulalah yang telah menanamkan garis pengarah sikap kita terhadap berbagai masalah maupun terhadap suatu objek psikologi.

Berdasarkan hasil analisis data primer, dapat dilihat nilai $t$ hitung $(1,742)<t$ tabel $(2,002)$, pada taraf signifikansi $95 \%$ dengan nilai $r_{s}$ sebesar 0,223, sehingga dapat disimpulkan bahwa terdapat hubungan yang tidak signifikan antara terpaan media massa dengan sikap petani wortel terhadap keberadaan Sub Terminal Agribisnis (STA) Watusambang. Tingkat terpaan media massa tidak menentukan sikap petani wortel terhadap keberadaan Sub Terminal Agribisnis (STA) Watusambang.

Namun penelitian ini tidak sesuai dengan pendapat Sarwono (2011), bahwa banyak sikap yang terbentuk akibat dari pengamatan terhadap berita, gambar melalui koran, televisi, majalah dan media massa lainnya. Walaupun diadakan peningkatan kuantitas maupun kualitas media massa tidak akan membuat sikap petani wortel terhadap keberadaan Sub Terminal Agribisnis (STA) Watusambang semakin baik. Walaupun tingkat terpaan media 


\section{Jurnal Agritexts Volume 42 Nomer 2 Oktober 2018}

massa dalam kategori tinggi, namun informasi yang didapat oleh petani wortel belum sesuai dengan yang dibutuhkan oleh petani wortel dalam memperbaiki usahatani wortel termasuk pemasaran wortel. Sehingga informasi adanya pasar lelang (Terminal Agribisnis/ Sub Terminal Agribisnis), informasi harga wortel dipasar, informasi perencanaan usahatani wortel masih kurang didapatkan oleh petani wortel. Banyak maupun sedikit petani mengakses informasi pertanian yang ada di media massa, tidak akan merubah keputusan dan pikiran petani dalam memperbaiki sikapnya terhadap keberadaan STA Watusambang.

\section{KESIMPULAN DAN SARAN}

\section{Kesimpulan}

Berdasarkan hasil penelitian mengenai sikap petani wortel terhadap Keberadaan Sub Terminal Agribisnis (STA) Watusambang di Kecamatan Tawangmangu Kabupaten Karanganyar, diperoleh kesimpulan sebagai berikut:

Sikap petani wortel terhadap Keberadaan Sub Terminal Agribisnis (STA) Watusambang di Kecamatan Tawangmangu Kabupaten Karanganyar termasuk dalam kategori netral dengan rincian yaitu: sikap petani wortel terhadap tujuan STA dalam kategori baik (sebesar 33,3\%); sikap petani wortel terhadap pelaksanaan dan manfaat STA dalam kategori buruk (40\% dan 41,7\%).

Faktor pembentuk sikap petani yaitu: umur tergolong umur 37-44 tahun (sebesar 35\%); pendidikan formal dan kebudayaan termasuk kategori rendah (sebesar 38,3\% dan $51,7 \%)$; pengalaman pribadi dan pengaruh orang lain yang dianggap penting termasuk kategori rendah (sebesar $43,3 \%$ dan $41,9 \%$ ); sedangkan terpaan media massa termasuk kategori tinggi (sebesar 51,7\%).

Hubungan antara faktor pembentuk sikap terhadap sikap petani wortel terhadap keberadaan Sub Terminal Agribisnis (STA) sebagai berikut: pengalaman pribadi, pengaruh orang lain yang dianggap penting, dan kebudayaan memiliki hubungan yang sangat signifikan $(\alpha=0,01)$ dengan sikap petani wortel terhadap STA Watusambang; sedangkan umur, pendidikan formal, dan terpaan media massa memiliki hubungan yang tidak signifikan dengan sikap petani wortel terhadap STA Watusambang.

\section{Saran}

Adapun saran yang dapat diberikan oleh peneliti yaitu:

Bagi pemerintah, untuk meningkatkan efektifitas Sub Terminal Agribisnis (STA) seyogyanya menampung aspirasi petani tentang apa yang sebenarnya dibutuhkan dan dalam pembangunan Sub Terminal 
Prihatin, Lestari, Ihsaniyati, Agribisnis; Pasar; Petani; Rank,,,

Agribisnis (STA) di wilayah lain hendaknya selalu melibatkan petani dalam setiap tahap pembangunannya termasuk tahap perencanaan, pelaksanaan, dan pemanfaatan hasil.

Bagi petani, hendaknya lebih aktif dalam mencari informasi baik mengenai budidaya maupun pemasaran wortel kepada orang-orang yang dianggap penting termasuk kepada PPL dan ketua kelompok tani serta petani hendaknya lebih aktif dalam mencari informasi pasar wortel termasuk informasi terbaru tentang harga wortel.

\section{DAFTAR PUSTAKA}

Azwar, Syaifuddin. 1995. Seri Psikologi: Sikap Manusia Teori dan Pengukuranya. Yogyakarta: Penerbit Liberty

BPS Kabupaten Karanganyar. 2017. Kabupaten Karanganyar Dalam Angka 2015.https://karangan yarkab.bps.go.id/index.php/pu blikasi/137. Diakses pada tanggal 30 Oktober 2017

Kementrian Pekerjaan Umum. 2012. Agropolitan dan Minapolitan Konsep Kawasan Menuju Keharmonisan. http://ciptakary a.pu.go.id/bangkim/old file/v2 /download/ebook/Buku_Agro_ Mina_2012.pdf?iframe=true\& width $=1400$ \& height $=650$. Diaks es Tanggal 2 Maret 2017.

Mahmud, MD. 1990. Psikologi Suatu Pengantar. BPFE. Yogyakarta Notoatmodjo. 2003. Pendidikan dan Perilaku Kesehatan. Rineka. Cipta Jakarta.

Sarwono, Sarlito W dan Eko A. Meinarno. 2011. Psikologi Sosial. Jakarta: Salemba Humanika.

Soekartawi. 1984. Prinsip Dasar Komunikasi Pertanian. Bogor: IPB.

Zuchdi, Darmiyati. 1995. Pembentuk Sikap. Cakrawala Pendidikan No. 3 Tahun XIV : 51-63 